\title{
Tam ve Kısıtlı Sulama Uygulamalarının Fasulye (Phaseolus vulgaris L.) Çeșitlerinde Tohum Çimlenmesi ve Fide Gelișimine Etkisi
}

\author{
*Sevgi ÇALIŞKAN', Ramazan İlhan AYTEKIN", Mehmet Emin ÇALIȘKAN² \\ ${ }^{1}$ Niğde Ömer Halisdemir Üniversitesi, Ayhan Şahenk Tarım Bilimleri ve Teknolojileri Fakültesi, \\ Bitkisel Üretim ve Teknolojileri Bölümü, Niğde \\ ${ }^{2}$ Niğde Ömer Halisdemir Üniversitesi, Ayhan Şahenk Tarım Bilimleri ve Teknolojileri Fakültesi, \\ Tarımsal Genetik Mühendisliği Bölümü, Niğde \\ *Sorumlu yazar e-posta (Corresponding author e-mail): scaliskan@ohu.edu.tr
}

Öz

Çalıșma, tam ve kısıtlı sulama koșullarında yetiștirilen farklı fasulye çeșitlerinden elde edilen tohumlarda çimlenme ve fide gelișimini belirlenmek amacıyla Niğde Ömer Halisdemir Üniversitesi Tarım Bilimleri ve Teknolojileri Fakültesi Laboratuarında yürütülmüștür. Çalıșmada sekiz farklı fasulye çeșidi kullanılmıștır. Laboratuvarda ekimden sonra 8. günde tohumlarda, çimlenme oranı (\%), çimlenme indeksi, ortalama çimlenme süresi (gün), kök ve sap uzunluğu (cm) ve sap ve kök kuru ağırlığına (mg/bitki) ilișkin ölçümler yapılmıștır. Çalıșma sonucunda, tam sulama koșulları altında yetiștirilen fasulye tohumlarında çimlenme oranı \%97 ile \%100 arasında, kısıtlı sulama koșulları altında yetiștirilen fasulye tohumlarında ise \%83 ile \%94 arasında değișmiștir. Tam sulama koșulları altında yetiștirilen Noyanbey 98 çeșidine ait tohumlar en yüksek çimlenme oranına (\%100) sahip olurken; kısıtlı sulama koșulları altında yetiștirilen Zirve çeșidine ait tohumların en yüksek çimlenme oranına (\%94) sahip olduğu belirlenmiștir. Çalıșmada, kısıtlı sulama koșulları altında yetiștirilen farklı fasulye çeșitlerinden elde edilen tohumların fide ve kök gelișimlerinin daha düșük olduğu belirlenmiștir.

Anahtar Kelimeler: Phaseolus vulgaris L., kuraklık, ana bitki, çimlenme oranı

\section{The Effect of Full and Limited Irrigation Treatments on Seed Germination and Seedling Growth of Common Bean Cultivars (Phaseolus vulgaris L.)}

\section{Abstract}

The aim of the present study is to determine of the seed germination and seedling development of different dry bean genotypes, grown under full and limited irrigation conditions. The study was conducted at Niğde Ömer Halisdemir University laboratories. Eight different dry bean cultivars were used in the study. At the 8th day; germination rate (\%), germination index, mean germination time (day), root and shoot length $(\mathrm{cm})$, and shoot and root fresh and dry weight (mg/plant) were measured. As a result, germination rates in bean seeds grown under full irrigation conditions ranged from $97 \%$ to $100 \%$ and in bean seeds grown under limited irrigation conditions from $83 \%$ to $94 \%$. It has been determined that the seeds of Noyanbey 98, grown under full irrigation conditions, have the highest germination rate $(100 \%)$ and the seeds of the Zirve, grown under limited irrigation conditions, have the highest germination rate $(94 \%)$. In the study, it was determined that seedling and root growth of seeds obtained from different bean cultivars grown under limited irrigation conditions were lower.

Keywords: Phaseolus vulgaris L., drought, main plant, germination rate 


\section{Giriș}

$\mathrm{B}$ itki çoğaltımının en temel organı olan tohum, birçok fizyolojik ve biyokimyasal özelliğe sahip olup, üretimin hem bașlangıç materyali ve hem de son materyalidir. Tohum olușumu generatif dönem ile bașlamakta ve ana bitkinin yașadığı çevreden önemli ölçüde etkilenmektedir (Bewley and Black, 1994). Ekim esnasında kullanılan tohumluğun kalitesi, tohumluğun üretimi esnasındaki çevresel faktörler ile hasat ve depolama esnasında tohumun maruz kaldığı koșullara bağlıdır. Tarlada tohum büyümesi ve gelișmesi esnasında uygun olmayan çevre koșulları (kuraklık, yüksek sıcaklık, nem) tohumun çimlenme ve canlıı̆ını azaltabilir (Egli ve ark., 2005).

Kuraklık, bitki büyümesini, gelișimini ve verimliliği sınırlandıran önemli bir faktördür. Tohum gelișimi esnasında meydana gelen kuraklık tohum kalitesini azaltır (Dornbos et al., 1989; Smicklas et al., 1992; Heatherly, 1993; Egli ve ark., 2005). Baklagillerde generatif dönem kuraklık stresine en hassas dönemdir (Castanede et al., 2006). Fasulye bitkisinde, çiçek olușumu, tam çiçeklenme, meyve olușumu ve dane dolum döneminde meydana gelen kuraklık stresinin ürün veriminde $\% 40$ 60 oranında kayba neden olmuștur (Acosta et al., 2004; Nunez et al., 2005). Verim azalmasının bitki bașına meyve sayısı (\%63.3), meyve bașina tohum sayısı (\%28.9) ve tohum ağırlı̆ından $(\% 22,3)$ kaynaklandığı bildirilmiștir (Nunez et al., 2005). Kuraklık stres koșulları altında, fasulyede stoma iletkenliğinin azalması gibi fizyolojik değișimler ortaya çıkar. Bu da transpirasyonda ve fotosentezde azalmaya ve bunun sonucu büyüme ve gelișmede kullanılan șekerin azalmasına neden olur (Castaneda et al., 2009). Kurak koșullara maruz kalan fasulye tohumlarının tohum ağırlığında \%24 ve tohum hacminde \%19'luk bir azalmanın meydana geldiği bildirilmiștir (Perez et al., 1999). Castaneda et al. (2009), kuraklık stresinin tohumun çimlenme kapasitesini etkilemeksizin tohumda birikmiș rezerv miktarını \%8 ile \%12 arasında azalttığını bildirmiștir. Heatherly (1993), generatif dönemde kuraklık stresine maruz kalan soya tohumlarında çimlenmenin \%80'nin altına düștüğünü bildirmiștir. Vieira et al. (1992), benzer șekilde kuraklık stresine maruz kalan tohumlarda olgunlașmamıș, burușuk, mat kabuklu tohum sayısının yüksek olmasına rağmen kuraklık stresinin tohum canlılığı ve çimlenme üzerine etkisinin olmadığını bildirmiștir Dornbos et al. (1989), kuraklığa maruz kalmıș soya bitkilerinden elde edilen tohumlarda çimlenmede $\% 12$ ve tohum canlılı̆ında \%5 oranında azalmanın meydana geldiğini, yine Lin and Markhart (1996), kurak ve yüksek sıcaklık stresi altında yetiștirilen iki fasulye türünün ( $P$. vulgaris ve $P$. acutifolius) tohumların çimlenmesinde \%11 azalma tespit ettiğini bildirmișlerdir.

Bu çalıșmada, çiçeklenme, meyve olușumu ve dane dolum döneminde kuraklığa maruz kalmıș fasulye tohumlarında çimlenme ve fide gelișimlerinin belirlenmesi amaçlanmıștır.

\section{Materyal ve Yöntem}

Araștırma, Niğde Ömer Halisdemir Üniversitesi Ayhan Şahenk Tarım Bilimleri ve Teknolojileri Fakültesi laboratuarlarında yürütülmüștür. Çalıșmada, kuraklık uygulaması ve normal sulama uygulamasından elde edilen sekiz farklı fasulye çeșidinin tohumları materyal olarak kullanılmıștır.

Kuraklık ve normal sulama uygulamasından elde edilmiș olan fasulye tohumları petri kaplarında çimlendirme denemeleri yapılmıștır. Çimlendirme denemeleri (ISTA 1996) tarafından belirlenen standartlara göre yürütülmüștür.

Çimlendirme denemelerine bașlamadan önce tohumlar tartılarak 100 tohum ağırlıkları tespit edilmiștir. Deneme, tesadüf parselleri deneme desenine göre üç tekrarlamalı olarak kurulmuștur. Çimlendirme ortamı olarak, içerisine kurutma kağıdı yerleștirilmiș $10 \mathrm{~cm}$ çapında cam petri kapları kullanılmıștır. Her bir petri kabına 25 adet tohum bırakılmıș ve $10 \mathrm{ml}$ saf su ilave edilerek $25 \pm 0.5^{\circ} \mathrm{C}$ 'lik sabit ortam sıcaklığındaki iklim odasına yerleștirilmiștir. Her gün petri kapları kontrol edilerek belirli aralıklarla $10 \mathrm{ml}$ saf su ilavesi yapılmıștır. Her gün petri kapları aynı saatte kontrol edilerek çimlenen tohumlar sayılmıș ve $2 \mathrm{~mm}$ kökçük uzunluğuna sahip tohumlar çimlenmiș olarak kabul edilmiștir. Sekizinci günde toplam çimlenen tohumlar sayılarak çimlenme yüzdesi (\%) belirlenmiștir. Çimlenme indeksi $(C ̧ i)=\left(8 x_{n 1}+\right.$ $\left.7 \mathrm{x}_{\mathrm{n} 2}+\ldots \ldots \ldots \ldots \ldots . . .+1 \mathrm{x}_{\mathrm{n} \delta}\right) /($ toplam çimlendirme gün sayısı $\mathrm{x}$ çimlendirmede kullanılan tohum sayısı) 
formülüyle hesaplanmıștır (Mares and Mrva, 2001). Formülde, $n 1, n 2, n 3, \ldots \ldots . . n 8$, 1. gün, 2. gün, 3. gün ve 8 . gündeki çimlenen tohum sayısını ifade etmektedir. Ayrıca çimlenme hızını belirlemek amacıyla ortalama çimlenme süresi (OÇS) Ellis and Roberts (1980)'e göre hesap edilmiștir. Ayrıca çimlenme testi sonunda (10. günde) kök ve fide uzunlukları ile kök ve fide kuru ağırlık değerleri belirlenmiștir. Bitkilerde kök ve fide kuru ağırlıkları, örnekler cam petri kaplarına konmuș ve ağzı cam kapakla kapatılarak $70^{\circ} \mathrm{C}$ 'de 48 saat bekletildikten sonra alınmıș ve tartıımıștır.

Incelenen özelliklere ait veriler JMP istatistik programı kullanılarak analiz edilmiș, ortalamaların karșılaștııılması LSD testine göre yapılmıștır.

\section{Bulgular ve Tartıșma}

Tam ve kısıtlı sulama uygulamalarından elde edilmiș fasulye tohumlarında yapılan çimlendirme denemesi sonucu saptanan 100 tohum ağırlığı (g), sap uzunluğu $(\mathrm{cm})$ ve kök uzunluğuna $(\mathrm{cm})$ ilișkin değerler Çizelge 1'de verilmiștir.

Çizelge 1'in incelenmesinden de görüldüğü gibi; tam sulama yapılan uygulamalardan elde edilen tohumlukların 100 tohum ağırlıkları, kısıtlı sulama uygulaması yapılan tohumluklardan elde edilenlere göre daha yüksek olmuștur. Tam sulama yapılan uygulamalardan elde edilen tohumluklarda en yüksek 100 tohum ağırlı̆ı $50.1 \mathrm{~g}$ ile Cihan çeșidinde, kısıtlı su uygulamasında da yine $43.9 \mathrm{~g}$ ile Cihan çeșidinden elde edilmiștir. Fasulyede kısıtlı sulamanın 100 tohum ağırığını azalttığı (Golezani and Oskooyi, 2008), (Saucedo et al., 2009) ile (Rezene et al., 2011) tarafından da bildirilmektedir. Tam ve kısitlı su uygulamalarından elde edilen tohumlukların sap ve kök uzunlukları bakımından çeșitler arasında önemli farklılıklar olușmuștur. Denemede kullandığımız tüm çeșitlerde tam sulama yapılan uygulamadan elde edilen tohumların kök ve sap uzunluk değerleri kısıtlı sulama yapılan uygulamadan elde edilen tohumluklardan daha yüksek olmuștur. Tam su uygulamasından elde edilen tohumluklarda en yüksek sap uzunluğu 17.1 cm ile Arslan, en yüksek kök uzunluğu 16,7 $\mathrm{cm}$ ile Cihan çeșidinden elde edilmiștir. Kısıtı su uygulamasından elde edilen tohumluklarda ise en yüksek sap uzunluğu $10.4 \mathrm{~cm}$ ile Arslan, en yüksek kök uzunluğu ise $10.5 \mathrm{~cm}$ ile Noyanbey 98 çeșidinden elde edilmiștir (Çizelge 1). Tohumların kuraklık, sıcaklık gibi stres faktörlerinden olumsuz etkilendiği

Çizelge 1. Tam ve kısıtlı sulama uygulamalarından elde edilen fasulye tohumlarının 100 tohum ağırlığı, sap uzunluğu ve kök uzunluğuna ilișkin ortalama değerler Table 1. Average values of 100 seed weight, stem length and root length of dry bean seeds obtained from full and limited irrigation applications

\begin{tabular}{|c|c|c|c|c|c|c|}
\hline \multirow[b]{2}{*}{ Çeșit-Uyg. } & \multicolumn{2}{|c|}{100 tohum ağırlığı (g) } & \multicolumn{2}{|c|}{ Sap uzunluğu (cm) } & \multicolumn{2}{|c|}{ Kök uzunluğu (cm) } \\
\hline & Kontrol & Kurak & Kontrol & Kurak & Kontrol & Kurak \\
\hline Yunus 90 & $45.8 \mathrm{c}$ & $40.5 \mathrm{~b}$ & $10.2 \mathrm{c}$ & $6.7 \mathrm{e}$ & $13.1 \mathrm{bc}$ & $8.1 \mathrm{~b}$ \\
\hline Cihan & $50.1 \mathrm{a}$ & $43.9 \mathrm{a}$ & $9.8 \mathrm{c}$ & $6.2 \mathrm{e}$ & $16.7 \mathrm{a}$ & $5.0 \mathrm{de}$ \\
\hline Göynük 98 & $46.9 \mathrm{bc}$ & $40.1 \mathrm{~b}$ & $10.3 c$ & $7.1 \mathrm{de}$ & $15.1 \mathrm{ab}$ & $6.1 \mathrm{cde}$ \\
\hline Alberto & $36.2 f$ & 34.9 e & $13.4 \mathrm{~b}$ & $9.5 a b$ & $15.5 a b$ & $8.0 \mathrm{bc}$ \\
\hline Batalla & $39.0 \mathrm{e}$ & $36.0 \mathrm{~d}$ & $11.7 \mathrm{bc}$ & $8.0 \mathrm{~cd}$ & $13.3 \mathrm{bc}$ & $6.8 \mathrm{bcd}$ \\
\hline Zirve & $43.1 \mathrm{~d}$ & $38.6 \mathrm{c}$ & $13.8 \mathrm{~b}$ & $9.8 \mathrm{a}$ & $11.2 \mathrm{c}$ & 4.3 e \\
\hline Arslan & $42.3 d$ & $38.9 \mathrm{c}$ & $17.1 \mathrm{a}$ & $10.4 \mathrm{a}$ & $12.7 \mathrm{bc}$ & $5.1 \mathrm{de}$ \\
\hline Noyanbey 98 & $47.2 \mathrm{~b}$ & $40.2 \mathrm{~b}$ & $13.0 \mathrm{~b}$ & $8.5 \mathrm{bc}$ & $17.6 \mathrm{a}$ & $10.5 \mathrm{a}$ \\
\hline Ortalama & 43.8 & 39.1 & 12.4 & 8.2 & 14.4 & 6.7 \\
\hline LSD (\%5) & 1.252 & 0.860 & 2.539 & 1.256 & 3.249 & 1.948 \\
\hline Tekerrür & 0.516 & 0.296 & 1.287 & 1.053 & 0.975 & 5.429 \\
\hline Çeşit & $84.40^{\star \star}$ & $31.299^{\star *}$ & $24.19^{\star \star}$ & $9.591^{\star *}$ & $19.11^{\star \star}$ & $16.671^{\star \star}$ \\
\hline Hata & 0.725 & 0.342 & 2.981 & 0.730 & 4.883 & 1.755 \\
\hline DK (\%) & 1.941 & 1.494 & 13.864 & 10.294 & 15.314 & 19.548 \\
\hline
\end{tabular}

${ }^{*}: p<0.05,{ }^{* *}: p<0.01$ 
bilinmektedir. Bu tip çevresel faktörlerden etkilenen tohumların tohumluk olarak kullanılması sonucu tohumda bozulmalar ve tohum yașlanması gibi olumsuz etkiler meydana gelmektedir. Fasulyede bu șekilde ana bitkinin yetișme dönemi içerisinde stres faktörlerinden etkilenmesi sonucu tohumların tohumluk olarak kullanılması bitkilerin sap ve kök uzunluğunun normal koșullardan üretilen tohumluklara göre daha düșük olduğu Balaneji and Sedghi (2012) tarafından bildirilmiștir. Yine ana bitkide yașanan su eksikliğinin kök ile sap uzunluğunu azalttığı Mut ve Akay (2010) tarafından yapılan çalıșma ile ortaya konmuștur.

Tam ve kısıtlı sulama uygulamalarından elde edilmiș fasulye tohumlarında yapılan çimlendirme denemesi sonucu saptanan sap yaș ağırlık (g), sap kuru ağırlık (g), kök yaș ağırlık (g) ve kök kuru ağırlığına (g) ilișkin değerler Çizelge 2'de verilmiștir.

Çalıșmamızda tam ve kısıtlı su uygulamaları elde edilen tohumların sap yaș ağırlığı, sap kuru ağırlığı, kök yaș ağırlığı ve kök kuru ağırlı̆ı̆ üzerine önemli etkide bulunmuș ve çeșitlere bağlı olarak bu değerler önemli derecede değișmiștir (Çizelge 2). Tam sulama uygulamasından elde edilen tohumlarda, en yüksek sap yaș ağırlık $1.69 \mathrm{~g}$ ile Yunus 90 çeșidinden elde edilirken; kısıtlı sulama uygulamasından elde edilen tohumlarda 1.22 $g$ ile Zirve çeșidinden elde edilmiștir. Sap kuru ağırlık değerleri bakımından çeșitler benzer sonuçlar göstermișlerdir. Tam su uygulamasından elde edilen tohumlarda en yüksek kök yaș ağırlığı $1.03 \mathrm{~g}$ ile Arslan çeșidinden ve kısıtlı su uygulamasından elde edilen tohumlarda ise en yüksek değer $0.47 \mathrm{~g}$ ile Yunus 90 çeșidinden elde edilmiștir (Çizelge 2). Bitkilerin kısıtı su koșullarına maruz kalması ya da bitki bünyesindeki su potansiyelinin azalması sonucu kök yaș ve kuru ağırlık ile sap yaș ve kuru ağırlık değerlerinin azaldığını Liu et al. (2015) bildirmektedir. Yine kuraklık ve sıcaklık gibi stres faktörlerine maruz kalan bitki tohumlarının sap yaș ve kuru ağırlık değerleri ile kök yaș ve kuru ağırlık değerlerinin normal koșullarda yetișen bitki tohumlarından elde edilen değerlere göre daha düșük olduğu ve fide gelișimlerinin stres koșullarından olumsuz etkilendiği Balaneji and Sedghi (2012) tarafından bildirilmiștir.

Tam ve kısıtlı sulama uygulamalarından elde edilmiș fasulye tohumlarında yapılan

Çizelge 2. Tam ve kısıtlı sulama uygulamalarından elde edilen fasulye tohumlarının sap yaș ve kuru ağırlık ile kök yaș ve kuru ağırlıklara ilișkin ortalama değerler

Table 2. Average values of fresh and dry weight of stem and root of dry bean seeds obtained from full and limited irrigation applications

\begin{tabular}{|c|c|c|c|c|c|c|c|c|}
\hline \multirow[b]{2}{*}{ Çeşit-Uyg. } & \multicolumn{2}{|c|}{ Sap yaș ağırlık (g) } & \multicolumn{2}{|c|}{ Sap kuru ağırlık (g) } & \multicolumn{2}{|c|}{ Kök yaș ağırlık (g) } & \multicolumn{2}{|c|}{ Kök kuru ağırlık (g) } \\
\hline & Kontrol & Kurak & Kontrol & Kurak & Kontrol & Kurak & Kontrol & Kurak \\
\hline Yunus 90 & $1.69 \mathrm{a}$ & $1.00 \mathrm{~b}$ & $0.21 \mathrm{a}$ & $0.12 \mathrm{a}$ & $0.69 \mathrm{c}$ & $0.47 \mathrm{a}$ & $0.083 a$ & $0.051 \mathrm{a}$ \\
\hline Cihan & $1.57 \mathrm{ab}$ & $0.58 d$ & $0.21 \mathrm{a}$ & $0.06 \mathrm{~d}$ & $0.74 \mathrm{bc}$ & $0.20 \mathrm{c}$ & $0.077 \mathrm{a}$ & $0.026 \mathrm{bc}$ \\
\hline Göynük 98 & $1.36 \mathrm{~cd}$ & $0.81 \mathrm{c}$ & $0.13 \mathrm{~cd}$ & $0.08 \mathrm{c}$ & $0.53 \mathrm{~d}$ & $0.22 \mathrm{c}$ & $0.054 \mathrm{~b}$ & $0.023 \mathrm{c}$ \\
\hline Alberto & $1.27 \mathrm{~d}$ & $0.91 \mathrm{bc}$ & $0.12 \mathrm{~d}$ & $0.07 \mathrm{~cd}$ & $0.73 \mathrm{bc}$ & $0.31 \mathrm{bc}$ & $0.076 \mathrm{a}$ & 0.032 b \\
\hline Batalla & $1.24 \mathrm{~d}$ & $0.94 \mathrm{bc}$ & $0.12 \mathrm{~d}$ & $0.08 \mathrm{c}$ & $0.61 \mathrm{~cd}$ & $0.26 \mathrm{bc}$ & $0.071 \mathrm{a}$ & $0.027 \mathrm{bc}$ \\
\hline Zirve & $1.58 \mathrm{a}$ & $1.22 \mathrm{a}$ & $0.16 \mathrm{~b}$ & $0.10 \mathrm{~b}$ & $0.86 \mathrm{~b}$ & $0.34 b$ & $0.080 \mathrm{a}$ & $0.030 \mathrm{bc}$ \\
\hline Arslan & $1.26 \mathrm{~d}$ & 1.04 b & $0.14 \mathrm{bc}$ & $0.09 \mathrm{~b}$ & $1.03 \mathrm{a}$ & $0.36 a b$ & $0.079 \mathrm{a}$ & $0.030 \mathrm{bc}$ \\
\hline Noyanbey 98 & $1.44 \mathrm{bc}$ & $0.92 \mathrm{bc}$ & $0.13 \mathrm{~cd}$ & $0.08 \mathrm{c}$ & $0.84 \mathrm{~b}$ & $0.35 \mathrm{~b}$ & $0.081 \mathrm{a}$ & $0.028 \mathrm{bc}$ \\
\hline Ortalama & 1.42 & 0.92 & 0.15 & 0.08 & 0.75 & 0.31 & 0.075 & 0.030 \\
\hline LSD (\%5) & 0.144 & 0.132 & 0.018 & 0.011 & 0.132 & 0.114 & 0.014 & 0.007 \\
\hline Tekerrür & 0.010 & 0.001 & 0.00006 & 0.00009 & 0.022 & 0.017 & 0.0001 & 0.00003 \\
\hline Çeşit & $0.116^{\star \star}$ & $0.136^{\star \star}$ & $0.0055^{\star \star}$ & $0.0013^{\star \star}$ & $0.095^{\star \star}$ & $0.030^{\star *}$ & $0.0003^{*}$ & $0.00029^{\star *}$ \\
\hline Hata & 0.009 & 0.008 & 0.0001 & 0.00006 & 0.008 & 0.006 & 0.0001 & 0.00002 \\
\hline DK (\%) & 6.846 & 9.678 & 8.141 & 8.692 & 11.916 & 24.570 & 13.363 & 15.721 \\
\hline
\end{tabular}

*: $p<0.05,{ }^{* *}: p<0.01$ 
çimlendirme denemesi sonucu saptanan çimlenme oranı (\%), ortalama çimlenme süresi (gün) ve çimlenme indeksine (\%) ilișkin değerler Çizelge 3'te verilmiștir.

Çizelge 3'ün incelenmesinden de görüldüğü gibi; çimlenme oranı değerleri tam sulama uygulamasından elde edilen tohumluklarda \%97 ile \%100 arasında değișmiș fakat istatistiki olarak önemli bir farklılık bulunmamıștır. Kısıtlı sulama uygulamasından elde edilen tohumluklarda ise çeșitler arasındaki farklılıklar istatistiki olarak önemli bulunmuștur. Kısıtlı sulama uygulanan tohumluklarda genel olarak denemede kullanılan tüm çeșitlerde çimlenme oranı tam sulama koșullarından elde edilen tohumluklara göre daha düșük olmuștur. Tam ve kısıtlı sulama koșullarında üretilmiș fasulye tohumlarında ortalama çimlenme süreleri istatistiki olarak farklılık göstermiș ve kısıtlı sulama koșullarında elde edilen tohumların çimlenme süreleri gecikmiștir. Tam ve kısıtlı sulama uygulamalarından elde edilen tohumlukların çimlenme indeksi yönünden çeșitler arasındaki fark istatistiki yönden önemli bulunmuștur. En yüksek çimlenme indeksleri tam sulama uygulamasından elde edilirken, en küçük değerler kısıtlı sulama uygulamasından elde edilmiștir. Kuraklık stres koșulları altında fasulyede stoma iletkenliğinin azalmasına bağlı olarak transpirasyonda ve fotosentezde azalmanın meydana gelmesi sonucu büyüme ve gelișmede kullanılan șekerin azaldığı ve bunun sonucu olarak çimlenme oranının düștüğü bildirilmiștir (Castaneda et al., 2009). Kurak koșullara maruz kalan fasulye tohumlarının tohum ağırlığında \%24 ve tohum hacminde \%19'luk bir azalmanın meydana geldiği (Perez et al., 1999), kuraklık stresinin tohumun çimlenme kapasitesini etkilemeksizin tohumda birikmiș rezerv miktarını $\% 8$ ile $\% 12$ arasında azalttığı (Castaneda et al., 2009), generatif dönemde kuraklık stresine maruz kalan soya tohumlarında çimlenmenin \%80'nin altına düștüğü (Heatherly, 1993) bildirilmiștir. Dornbos et al. (1989), kuraklığa maruz kalmıș soya bitkilerinden elde edilen tohumlarda çimlenmede \%12 ve tohum canlılı̆ında \%5 oranında azalmanın meydana geldiğini, yine Lin and Markhart (1996), kurak ve yüksek sıcaklık stresi altında yetiștirilen iki fasulye türünün ( $P$. vulgaris ve $P$. acutifolius) tohumların çimlenmesinde $\% 11$ azalma tespit ettiklerini bildirmișlerdir.

Çizelge 3. Tam ve kısıtı sulama uygulamalarından elde edilen fasulye tohumlarının çimlenme oranı, ortalama çimlenme süresi ve çimlenme indeksine ilișkin ortalama değerler

Table 3. Average values of germination rate, mean germination time and germination index of dry bean seeds obtained from full and limited irrigation applications

\begin{tabular}{ccccccc}
\hline & \multicolumn{2}{c}{ Çimlenme oranı (\%) } & \multicolumn{2}{c}{ Çimlenme süresi (gün) } & \multicolumn{2}{c}{ Çimlenme indeksi (\%) } \\
\hline Çeşit-Uyg. & Kontrol & Kurak & Kontrol & Kurak & Kontrol & Kurak \\
\hline Yunus 90 & 98.0 & $85.0 \mathrm{~cd}$ & $3.7 \mathrm{~b}$ & $4.0 \mathrm{~b}$ & $0.83 \mathrm{a}$ & $0.70 \mathrm{ab}$ \\
Cihan & 97.0 & $90.0 \mathrm{abc}$ & $4.7 \mathrm{a}$ & $5.0 \mathrm{a}$ & $0.75 \mathrm{~d}$ & $0.69 \mathrm{bc}$ \\
Göynük 98 & 98.0 & $83.0 \mathrm{~d}$ & $4.7 \mathrm{a}$ & $4.7 \mathrm{~b}$ & $0.80 \mathrm{ab}$ & $0.65 \mathrm{c}$ \\
Alberto & 99.0 & $93.0 \mathrm{ab}$ & $4.0 \mathrm{~b}$ & $5.0 \mathrm{a}$ & $0.81 \mathrm{ab}$ & $0.74 \mathrm{a}$ \\
Batalla & 98.0 & $87.0 \mathrm{bcd}$ & $4.0 \mathrm{~b}$ & $5.0 \mathrm{a}$ & $0.76 \mathrm{~cd}$ & $0.60 \mathrm{~d}$ \\
Zirve & 99.0 & $94.0 \mathrm{a}$ & $4.0 \mathrm{~b}$ & $5.0 \mathrm{a}$ & $0.80 \mathrm{ab}$ & $0.72 \mathrm{ab}$ \\
Arslan & 98.0 & $93.0 \mathrm{ab}$ & $4.0 \mathrm{~b}$ & $5.0 \mathrm{a}$ & $0.79 \mathrm{bcd}$ & $0.69 \mathrm{bc}$ \\
Noyanbey 98 & 100.0 & $93.0 \mathrm{ab}$ & $4.0 \mathrm{~b}$ & $5.0 \mathrm{a}$ & $0.80 \mathrm{ab}$ & $0.73 \mathrm{ab}$ \\
Ortalama & 98.3 & 89.7 & 4.1 & 4.8 & 0.79 & 0.69 \\
LSD (\%5) & 3.551 & 6.003 & 0.471 & 0.259 & 0.040 & 0.043 \\
\hline Tekerrür & 3.166 & 24.666 & 0.031 & 0.031 & 0.0003 & 0.0020 \\
Çeşit & 3.357 & $71.714^{\star *}$ & $0.566^{\star *}$ & $0.495^{\star \star}$ & $0.0026^{\star}$ & $0.0089^{* *}$ \\
Hata & 5.833 & 16.666 & 0.102 & 0.031 & 0.0007 & 0.0008 \\
DK (\%) & 2.455 & 4.549 & 7.710 & 3.650 & 3.485 & 4.227 \\
\hline
\end{tabular}

${ }^{*}: p<0.05,{ }^{* *}: p<0.01$ 


\section{Sonuç}

Sonuç olarak; fasulye bitkisinde çiçeklenme, meyve olușumu ve dane dolumu döneminde meydana gelen kuraklık stresinin tohumun tohumluk kalitesini azalttığı, kuraklık stresine maruz kalan tohumların çimlenme oranlarının ve çimlenme indeksinin azaldığı, ortalama çimlenme süresinin uzadığı; bunun sonucu olarak da fide gelișimlerinin azaldığı belirlenmiștir.

\section{Kaynaklar}

Acosta-Diaz E., Acosta-Gallegos J.A., Padilla Ramirez J.S., 2004. Relacion raiz-vastago en frijol bajo dos condiciones de humedad. Agric. Técn. Méx. 30: 63-73

Amanpour-Balaneji B., and Sedghi M., 2012. Effect of aging and priming on physiological and biochemical traits of common bean (Phaseolus vulgaris L.). Notulae Scientia Biologicae, 4(2), 95

Badoni A., and Chauhan J.S., 2009. Study on seed germination growth and behavior of Brinjal in admiration to effect of NPK and organic manure. Nature and Science, 7 (5), 64-66

Bewley J.D., and Black M., 1994. Seed Development and Seed Maturation. In: Seeds: Physiology of Development and Germination (pp.35-110). Second Edition, Plenum Pres, New York and London

Castaneda-Saucedo M.C., Cordova-Téllez L., Gonzalez-Hernández V.A., Delgado-Alvarado A., Santacruz-Varela A., Garcia-de los Santos, G., 2006. Respuestas fisiologicas, rendimiento y calidad de semilla en frijol sometido a stres hidrico. Interciencia 31:461-466

Castaneda-Saucedo M.C., Cordova-Téllez L., Gonzalez-Hernández V.A., Delgado-Alvarado A., Santacruz-Varela A., Garcia-de los Santos, G., 2009. Physiological performance, yield and quality of dry bean seeds under drought stress. Interciencia, 34:748-754

Dornbos D.L. Jr., Mullen R.E., and Shibles R.M., 1989. Drought stress effects during seed fill on soybean seed germination and vigor. Crop Sci. 29:476-480. doi: 10.2135/ cropsci1989.0011183X002900020047x

Egli D.B., TeKrony D.M., Heitholt J.J., Rupe J., 2005. Air temperature During Seed Filling and Soybean Seed Germination and Vigor. Crop Science, 45:1329-1335

Ellis R.H., and E.H. Roberts., 1980. Towards a Rational Basis for Testing Seed Quality. In: Hebblethwaite, P.D. (Ed.), Seed Production. Butterworths, London, pp.605-635

\section{Teșekkür}

Bu çalıșmaya FEB 2015/05 numaralı proje ile finansal destek sağlayan Niğde Ömer Halisdemir Üniversitesi Bilimsel Araștırma Projeleri Birimine ve çalıșanlarına katkılarından dolayı teșekkür ederim.

Ghassemi-Golezani K., and Mazloomi-Oskooyi R., 2008. Effect of water supply on seed quality development in common bean (Phaseolus vulgaris var.). International Journal of Plant Production, 2(2), 117-124

Heatherly L.G., 1993. Drought stress and irrigation effects on germination of harvested soybean seed. Crop Sci. 33:777-781

ISTA, 1996. International Rules for Seed Testing. Seed Science and Technology. Zurich, Switzerland, 31:1-288. (Suppl.)

ISTA, 2005. International Rules for Seed Testing. International Seed Testing Association. Bassersdorf, Switzerland. $243 \mathrm{pp}$

Liu M., Li M., Liu K., and Sui N., 2015. Effects of drought stress on seed germination and seedling growth of different maize varieties. Journal of Agricultural Science, 7(5), 231. doi: http://dx.doi.org/10.5539/jas.v7n5p231

Mares D.J., and K Mrva., 2001. Mapping quantitative trait loci associated with variation in grain dormancy in Australian wheat. Crop Pasture Sci. 2001;52:1257-1265. doi: 10.1071/AR01049

Mut Z., and Akay H., 2010. Effect of seed size and drought stress on germination and seedling growth of naked oat (Avena sativa L.). Bulgarian Journal of Agricultural Science, 16(4), 459-467

Nunez Barrios A., Hoogenboom G., Nesmith D.S., 2005. Drought stress and distribution of vegetative and reproductive traits of a bean cultivar. Sci. Agric. (Piracicaba, Braz.) 62: 18-22

Perez H.P., Acosta D.E., Padilla R.S., Acosta G.J., 1999. Effect of drought on seed quality of common bean (Phaseolus vulgaris L.). Agric. Técn. Méx. 25: 107-114

Rezene Y., Gebeyehu S. and Zelleke H., 2011. Genetic variation for drought resistance in small red seeded common bean genotypes. Afr. Crop. Sci. J. 19, 303-312

Smicklas K.D., Mullen R.E., Carlson R.E., and Knapp A.D., 1992. Soybean seed quality response to drought stress and pod position. Agron. J. 84:166-170 